\title{
A arma da teoria: pensamento africano e literatura
}

\author{
Roberto Vecchi* \\ Se a soberania política é necessária, a soberania científica talvez seja ainda \\ mais importante na África contemporânea. \\ Engelbert Mveng
}

O título desta reflexão traz uma homenagem e um problema. O tributo é a Amílcar Cabral, após 40 anos do seu assassinato, e a um texto de sua autoria, justamente famoso, apesar dos marcos do tempo funcionando como sinal histórico: "A arma da teoria", apresentado na " ${ }^{a}$ Conferência de Solidariedade dos Povos da África, da Ásia e da América Latina" (a famosa Tricontinental), que ocorreu em Havana em 1966. O problema que surge, ao mesmo tempo, é o de discutir, nestas notas, porque o discurso de Cabral dá relevância ao que poderíamos definir como uma filosofia da praxe, uma teoria que se combina com a ação "revolucionária" ou, como Cabral afirma,

\begin{abstract}
é na intenção de contribuir, embora modestamente, para esse debate, que apresentamos aqui a nossa opinião sobre os fundamentos e objectivos da libertação nacional relacionados com a estrutura social. Essa opinião é ditada pela nossa própria experiência de luta e pela apreciação crítica das experiências alheias. Àqueles que verão nela um carácter teórico, temos de lembrar que toda a prática fecunda uma teoria. E que, se é verdade que uma revolução pode falhar, mesmo que seja nutrida por teorias perfeitamente concebidas, ainda ninguém praticou vitoriosamente uma Revolução sem teoria revolucionária (CABRAL, 2008, p. 176, grifo nosso).
\end{abstract}

Os acentos, que lembram de perto trechos conhecidos dos estudos pós-coloniais sobre o papel da teoria, evocam também um outro pensamento seminal, o de Franz Fanon, matricial para a articulação da teoria cabralina. Fanon, de fato, em particular no ensaio de 1955, "Antilheses e africanos", observa que "na Martinica, a primeira experiência metafísica, ou se se prefere ontológica, coincidiu com a primeira experiência política" (FANON, 2006, p. 35-37, tradução nossa), mostrando assim não só que a filosofia está inscrita no confronto anticolonialista, mas também como ela se põe na historicidade vivencial da experiência metafísica - conjugando praxe e pensamento, em suma - que fundaria assim a hermenêutica da fi-

Professor titular de literatura portuguesa e brasileira no departamento de Línguas Literaturas e Culturas Modernas da Universidade de Bolonha, Itália. E-mail: roberto.vecchi@unibo.it. 
losofia africana contemporânea. Entre Cabral e Fanon, no eixo entre teoria e prática, o filósofo eritreu Tsenay Serequeberhan estabelece como elo dialético o que ele chama da "actuality of existence" (SEREqueberhan, 2003, p. 225).

A centralidade de Cabral, dentro do horizonte do pensamento africano, confirma que, em dado momento histórico (nos processos de libertação), o pensamento dos nacionalistas das colónias portuguesas compartilhava muitas das preocupações dos pensadores africanos e não só de outros contextos coloniais, embora isto ocorra com alguns problemas e talvez equívocos.

Por exemplo, para perceber esta evidência, é suficiente folhear o famoso reader da Blackwell, African philosophy: an antology, organizado por Emmanuel Chukwundi Eze, e reparar que Cabral, líder do Partido Africano da Independência da Guiné e Cabo Verde - PAIGC, é o único pensador de língua portuguesa contemplado, com seu texto "National liberation and culture: return to the source" (Cabral, 1998), palestra apresentada em 1970, em francês, como parte do Eduardo Mondlane Memorial Lecture Series na Universidade de Syracuse, um ano depois do assassinato do primeiro presidente da Frente de Libertação de Moçambique FRELIMO. Texto singular, portanto, só lateralmente associável ao espaço da língua portuguesa e que, diga-se de passagem, cria um equívoco conceptual relevante, se a sua ideia dominante for lida superficialmente ("return to the source"), aparentemente remetendo para uma procura de origens, de um arché enterrado no passado primordial, que na verdade está longe das intenções do autor: o texto alude, pelo contrário, a um retorno à vitalidade cultural das fontes do passado para a construção da libertação nacional, conforme destaca Massoni (2001, p. 168).

A presença única de Cabral coloca assim o problema da exiguidade do espaço para a filosofia ou o pensamento dentro da experiência crítica das Áfricas que se expressam na pluralidade do português. Sobre o tema convergem as leituras que detetam uma hipotrofia da filosofia africana em língua portuguesa, em relação aos outros contextos anglófonos e, sobretudo, francófonos.

Estaríamos portanto, para esquematizar de modo bastante seco a questão, perante a insistência de um duplo problema no caso do pensamento africano referido à África portuguesa. Por um lado, haveria todo o conjunto de problemas que afeta, inclusive nominalmente, a chamada filosofia africana na sua não pacífica definição de um campo hermenêutico que não se identifique substancialmente com aquele hegemónico do Ocidente, sobre o qual se plasmaram também os álibis pseudo epistemológicos das narrações colonialistas e da primazia ocidental, num contexto como o africano, que se define por uma negatividade ontológica, a de não ser nem Ocidente nem Oriente, mas sendo parte de ambos os mundos. Por outro, a África de língua portuguesa, depois das lutas de independência (e dos pensamentos fortes que a estas lutas se referencializavam), não parece ter criado, depois do "evento africano" (MUdimBE, 2007, p. 69), uma versão ou uma "assimilação" (Laranjeira, 200o, p. viii) do que já tinha acontecido no caso da Negritude, ou seja, uma reformulação própria de um problema geral, que abrangia múltiplas lín- 
guas e culturas e investia a condição africana, mas que encontrava, dentro dos perímetros acanhados do colonialismo português, uma dicção própria e reconhecível.

Quanto ao primeiro problema que investe de modo geral todo o continente no seu "além" do colonialismo, Valentin Mudimbe, em The invention of Africa, escrito em 1988, traça um mapeamento do que foi a desmitologização de uma história africana inventada pelo exterior (MudimBE, 2007, p. 67). Deste ponto de vista, a revisão derivada das contribuições de Lévi-Strauss e Foucault (a partir de uma autocrítica pelo campo do inconsciente) permitiu a um grupo de filósofos africanos (predominantemente de língua francesa, como Paulin Hountondji de Benim ou Fabien Eboussi-Boulaga de Camarões, entre outros) desestabilizar o centralismo de significação de um sujeito universal (MUDIMBE, 2007, p. 68).

Esta "geração" do trânsito colonial, profissionalmente (do ponto de vista teórico) muito forte, promove um pensamento que vai além de uma teoria do ato emancipatório (concentrada na crítica da modernização europeia e das permanências residuais do passado colonial) e que, partindo de uma ideia da filosofia (Heidegger e Gadamer) como interpretação da mortalidade da experiência (MAssonI, 2001, p. 150), se constitui justamente como uma hermenêutica. Movimento este que favorece também a historicização crítica da etnofilosofia cujos momentos iniciais se encontram na célebre e ambígua Filosofia Bantu do franciscano belga Placide Frans Tempels (1944/2016) ou na sua atualização problemática sobre bases linguísticas por parte do filósofo ruandês Alexis Kagame (1956; 1976), conforme ressalta Mudimbe (2007, p. 206).

O que decorre deste quadro de formação e vocalização de uma "razão africana" é um processo próximo - pelo menos em alguns fragmentos - do que, em outros contextos, como, por exemplo, na Ásia meridional, se articula através de uma "provincianização da Europa", para usar a expressão mais divulgada de Dipesh Chakrabarty (2004), em que a Europa funciona como uma "figura imaginária", articulada a partir de formas esquemáticas e estereotípicas, que se localiza em outro contexto porque, anota o crítico indiano, "é impossível pensar o fenómeno da nossa modernidade política - a presença de instituições modernas quais o Estado, a burocracia e a empresa capitalística - sem recorrer a categorias e conceitos que afundam suas raízes nas tradições intelectuais, e até teológicas, europeias" (Chakrabarty, 2004, p. 16).

No quadro que se forma a partir do amadurecimento de uma crítica radical do sujeito (que não se nega ao diálogo com a teoria crítica europeia enquanto europeia) esclarece-se assim muito bem a "disputa sobre os universais" (CANNELLI, 2003, p. 55) que confuta a famosa (famigerada?) posição de Hegel (das Lições sobre a filosofia da história) de acordo com as quais "o que entendemos propriamente como África é aquele seu ser não histórico e não desenvolvido [...] onde ainda se está nos limiares da história do mundo" (CANNELLI, 2003, p. 135-136): um espaço, portanto, às margens da história. O contraste pode assumir o aspecto da impossibilidade do universal (Mudimbe) ou da sua falsidade (Eboussi Boulaga) ou de crí- 
tica do falso pluralismo (Hountondji), mas, ao mesmo tempo, depois da revisão dos falsos universalismos ocidentais, pode surgir uma possibilidade para repensar diferencialmente os valores universais: é o caminho que Fanon tinha já configurado, de certo modo, através de um humanismo produzido pela causa mundial dos oprimidos, mas que encontramos também em outros autores posteriores.

Valentin Mudimbe analisa sociologicamente o surto de um horizonte outro da filosofia africana, encontrando algumas recorrências exteriores: trata-se da geração posterior àquela da Negritude que interroga "a credibilidade da sua prise de parole" (MudimBE, 2007, p. 70). Em primeiro lugar, esta geração tem sua origem, na maioria dos casos, em famílias que pertencem à segunda ou terceira geração de cristãos africanos e parte deles são padres ou frequentaram instituições religiosas; em segundo lugar, receberam uma educação superior em algumas das melhores universidades europeias, em particular na França e na Bélgica, o que lhes possibilitou exercer, em vários casos, funções institucionais de altíssimo perfil (ocupando, portanto, posições de "poder") (MudimBE, 2007, p. 70-71).

Apesar de vários filósofos das ex-colónias portuguesas terem uma educação análoga (refiro-me à importância da Universidade gregoriana de Roma, onde muitos se doutoraram: Filomeno Lopes, Alfredo Manhiça, Severino Ngoenha), esta rearticulação do pensamento não ocorre no âmbito da África de língua portuguesa. As conjeturas possíveis são multíplices: é um enxerto positivo entre pensamentos críticos radicais da ex-metrópole no caso francês (o caso de Foucault é um dos mais relevantes), é também o contexto das modernidades africanas nas ex-colónias que cria as condições da formação de uma filosofia radicalmente crítica: o papel desenvolvido, por exemplo, por grupos como Présence africaine, fundada por Alioune Diop, representa um caso emblemático.

Poder-se-ia conjeturar que de um país como Portugal, que se define, como estereótipo, não filosófico, também o curso das ideias no contexto pós-colonial das suas ex-colónias (que não podem subsumir ferramentas teóricas radicais para a crítica do colonialismo) ressente-se desta lacuna de certo modo paradoxal (restaurando um elo com a metrópole); um efeito da condição semiperiférica, dir-se-ia. Mas seria um argumento banalizador e o caso de Cabral mostra que o problema provavelmente está mais deslocado desta aparência. Ou haveria outras condições por assinalar, como, por exemplo, as ambiguidades que sempre afetam as comunidades linguísticas, como a "Lusofonia", e que encobrem relações e dispositivos inclusive retóricos de poder e vontades hegemonizadoras, que parecem impedir e não favorecer "perspetivas inovadoras", segundo afirma Matumona (2011, p. 89).

O que é importante balizar, pelo contrário, é a não coincidência entre pensamento e filosofia que carateriza o espaço português. Aliás, num artigo de 2013, no jornal Público, António Guerreiro distingue polemicamente a categoria dos pensadores (que define de "realistas alucinados" como os poetas) daquela dos filósofos (caraterizados por terem sempre uma questão da linguagem em jogo): uma forma sútil de crítica à obra do "pensador por antonomásia", que é Eduardo Lourenço. 
Apesar de discutível, esta desmontagem funcionalista, que descrimina entre saberes e pensamentos, parece-me ter uma qualidade, aquela de encontrar uma disseminação do pensamento (criticável ao menos) noutros âmbitos também externos à assim chamada filosofia profissional.

E, talvez, a forma que mais preencheu - ou até às vezes vicariamente substituiu as fragilidades filosóficas, e não só no espaço da língua portuguesa, mas de maneira geral por todo o século XX, no Ocidente, como observa Franco Rella (1993, p. 147) - é a literatura. Uma literatura que tem funcionado como filosofia porque "a linguagem literária tem vindo a parecer um lugar de "hibridação" do pensamento mais próximo da "figura" do andersdenken do que não podia ser a filosofia em sentido estrito" (RELLA, 1993, p. 147). Que a literatura contenha este potencial reflexivo não vai em detrimento da valorização de todas as suas possibilidades estéticas.

As literaturas africanas em língua portuguesa são um campo que permite captar movimentos de pensamento que, em outros contextos, foi a filosofia contemporânea que fixou e, neste caso, se entrelaçam e "exemplificam" (dir-se-ia) nas figurações literárias. Para concluir, passo a um exemplo concreto que espero subtraia do abstrato esta proposta e discussão. Já no livro de Placide Temples sobre a ontologia bantu, emerge que um dos tópicos privilegiados da filosofia africana é a dimensão comunitária do ser humano (Processi, 2001, p. 91).

Trata-se também de um tema crucial para o pensamento contemporâneo em que a comunidade não é o que a sociedade perdeu ou quebrou, mas é o que nos acontece e o que se perde (a imanência de uma comunhão): é a perda constitutiva da própria comunidade (NANCY, 1992, p. 37). Reconfigurada assim, ela converte o essencialismo do "ser comum" que produziu os grandes monstros ideológicos do século XX, para a condição ontológica mais precária do "ser-em-comum", que reside no caráter permanentemente incompleto, não homogéneo, sujeito a constantes transformações, da ideia de comunidade; ela, portanto, não encontra seu princípio na construção plena, mas na incompletude, uma comunidade estruturada na falta, portanto désœuvrée, inoperante, sem obra. Ela é assim uma rede que não se reproduz como tal, mas que subsiste só em função da relação de uma singularidade com outras singularidades, de uma insuficiência com outras insuficiências e incompletudes. É isso que os põe "em-comum", mostrando uma comunidade que vem, como um "ser singular plural" (NANCY, 2001, p. 43), ou uma "singularidade qualquer" (AGAMBEN, 2001, p. 67), que não é mediada por um sentido de pertença ou uma identidade homogénea.

Se não encontramos essa dimensão teórica plenamente articulada do ponto de vista da teoria, ${ }^{1}$ encontramos em formas literárias fortemente soberanas, como

Em outros contextos, por exemplo, Achille Mbembe, num ensaio como "Necropolitics" (2003), aprofunda considerações sobre os limites da soberania e do biopoder na forma de subjugação contemporânea da vida que não pode prescindir do poder da morte: e atrás da teoria e da imagem 
a estória (a literatura breve), configurações de pensamento extraordinariamente agudas que modificam e vocalizam a ideia de comunidade.

É o que nos proporciona Luandino Vieira na famosíssima "A estória da galinha e do ovo" de Luuanda (1963), que pode ser assumido como um caso exemplar com amplas projeções noutros autores e noutros textos, onde o sentido político se amplifica, não só numa contextualização muito direta do colonialismo, mas pelo modo com que o ser-em-comum se retece, narrativamente, na situação de aberto conflito. A força da estória decorre da sua paradoxal incompletude, da debilidade, do fragmentarismo de uma imaginação comunitária que não se produz como obra, que não se configura como a totalidade orgânica no contexto fortemente degradado do musseque, onde, apesar do motivo folclórico, se encena um conflito. Ou seja, põe-se em jogo a discussão de uma norma (portanto também uma possível exemplaridade ou exceção) sobre a propriedade do ovo apesar do desrespeito natural das fronteiras por parte da galinha.

Os elementos que emergem, entre os muitos possíveis, são a dimensão política (e não económica no sentido da política aristotélica) das relações em campo, a impossibilidade de decidir sobre a norma, apesar do recurso à instância que num contexto político poderia pronunciar-se sobre a ambiguidade da norma (ou seja, estamos em suma no campo mais do trágico que do jurídico). Há uma latênciailatência da espacialidade política do musseque degradado que aparentemente seria gerido a partir de uma economia própria das relações privadas.

É oportuno evidenciar que o conflito, neste contexto, não dilacera uma obra ausente de uma comunidade que não se representa através de uma narração homogénea e organicamente constituída. As singularidades são dinâmicas, mas no desfecho percebemos que ocorre uma superação do conflito, não através de uma comunidade que preexiste ou que surge enquanto projeto, mas a partir de um ato de arbítrio e de violência que se abate em cima dela. Estamos muito além de qualquer possibilidade de uma imanência absoluta da comunidade que não chega a constituir-se como um embrião da nação a vir: uma comunidade que não se deixa imaginar como comunidade. É interessante porque ela transita por todas as instâncias do poder tradicional, de aparência, económico, religioso, mas não se compõe. O que a forma é justamente a debilidade, a incompletude, a resistência contra a violência do poder colonial que se abate contra ela. A comunidade que assim não se funda mas se põe em-comum, articula-se através do movimento e surge como contágio e paixão das singularidades, como a repensa Nancy.

Giorgio Agamben, num texto dedicado a repensar a comunidade que vem, depois dos fatos da praça Tienanmen, anota que o fato novo da política não é a luta para a conquista ou o controlo do estado, mas a luta entre o estado e o não-estado

de populações sujeitadas a condições de vida que os tornam "living dead" é fácil perceber o perfil continental de África. 
(a humanidade) "disjunção impreenchível das singularidades quaisquer e da organização estadual” (AgAmBen, 2001, p. 68). A multidão, da filosofia hobbesiana.

O desfecho da estória de Luandino, que transforma o conflito numa paradoxal força de configuração de uma comunidade não narrada e ainda inenarrável, testemunha um movimento antiessencialista do ser em-comum que, se quisermos, se situa também longe das reconstruções das comunidades imaginadas (que produzem a sua obra como projeto por vir, a descolonização, a nação):

Vovó Bebeca sorriu também. Segurando o ovo na mão dela, seca e cheia de riscos dos anos, entregou para Bina.

- Posso, Zefa?...

Envergonhada ainda, a mãe de Beto não queria soltar o sorriso que rebentava na cara dela. Pra disfarçar, começou dizer só:

- É, sim, vavó! É a gravidez. Essas fomes, eu sei... E depois o miúdo na barriga reclama!... De ovo na mão, Bina sorria. O vento veio devagar e, cheio de cuidados e amizades, soprou-lhe o vestido gasto contra o corpo novo. Mergulhando no mar, o sol punha pequenas escamas vermelhas lá embaixo nas ondas mansas da Baía. Diante de toda a gente e nos olhos admirados e monandengues de miúdo Xico, a barriga redonda e rija de nga Bina, debaixo do vestido, parecia era um ovo grande, grande...

Minha estória.

Se é bonita, se é feia, vocês é que sabem. Eu só juro que não falei mentira e estes casos passaram nesta nossa terra de Luanda (VIEIRA, 2004, p. 152).

A comunidade assim precariamente esboçada, mostra que a sua força é unicamente potência, resistência. $\mathrm{O}$ juramento final do narrador, que redefine pelo performativo a estória, evidencia o funcionamento do sacramento do poder enquanto sacramento da linguagem (AGAMBEN, 2008, p. 90) e a incompletude comunitária combina-se, pelo contrário, com uma força linguística que articula uma "poética" de relações" de singularidades. Uma singularidade que se apropria do seu próprio "ser-na-linguagem", recuando qualquer condição de identidade e de pertença e é antagonista ao "estado" (Agamben) onde as singularidades pacificamente manifestam o seu estar em-comum.

A estória encena seres em comum que não produzem a imagem da comunidade, mas acabam por renovar o vínculo comunitário a partir da incompletude. Notese que os coadjuvantes desta dimensão comunitária sem comunidade (imanente) são figuras alternativas, excluídas, marginais: miúdos ou dominados. Personagens que se caracterizam pela falta de força política, social, histórica, mas que acabam por acionar um outro instrumento de força, de uma "força débil" (para usar uma categoria do último Derrida, 2003, p. 195): "a cultura não hegemónica mas que acaba por funcionar como o efetivo meio de sobrevivência, (re)existência, afirmação de um grupo social improvável em termos de representação "comunitária". 
Literatura e pensamento assim combinados em Luandino Vieira ${ }^{2}$ não se distanciam muito do modo em que noutros contextos atua a filosofia por assim dizer profissional. O filósofo do Benim, Paulin Hountondji, ao reconstruir a missão da filosofia africana, observa como "para pensar a riqueza das tradições africanas, era necessário enfraquecer sem hesitações o conceito de África, libertá-lo de todas as suas conotações éticas, religiosas, filosóficas, políticas" (Mudimbe, 2007, p. 67), convidando assim a appauvrir (ou seja, empobrecer, ou justamente, enfraquecer, subtrair força) a noção (e as mitologias que sobre esta noção se depositaram) de África. O que o aproxima, observa Mudimbe, a posições críticas como as de Lévi Strauss e Foucault (MUDIMBE, 2007, p. 67).

Este exercício não só estético, mas, também, embora lateralmente, hermenêutico, a partir de um "si sem Édipo", como o definia Fanon, surge de modo recorrente também nas literaturas africanas que se expressam na língua portuguesa. Um horizonte aberto de reflexão que as torna, em muitos casos, com êxitos surpreendentes e encantadores, uma arma muito afiada e inesperada da teoria: literaturas a pleno título pensantes.

\section{Referências}

Agamben, Giorgio. La comunità che viene. Torino: Bollati Boringhieri, 2001.

Agamben, Giorgio. Il sacramento del linguaggio: archeologia del giuramento. Bari: Laterza, 2008.

CABral, Amílcar. National liberation and culture: return to the source. In: EzE, Emmanuel Chukwudi (ed.). African Philosophy: an anthology. Oxford: Blackwell, 1998. p. 260-266.

CABral, Amílcar. Documentário. Lisboa: Cotovia, 2008.

CANnelli, Barbara. Un pensiero africano: filosofi africani del novecento a confronto con l'Occidente (1934-1982). Milano: Leonardo International, 2003.

Chakrabarty, Dipesh. Provincializzare l'Europa. Tradução de M. Bortolini. Roma: Meltemi, 2004.

DerridA, Jacques. Stati canaglia: Due saggi sulla ragione. Tradução de L. Odello. Milano: Raffaello Cortina, 2003.

FANON, Frantz. Scritti politici: per la rivoluzione africana. Roma, DeriveApprodi, 2006.

2 Vieira como exemplo de muitas outras escritas, aliás não só africanas. Penso, por exemplo, na leitura solidária que se pode fazer sobre a comunidade inoperante num conto de Guimarães Rosa, "O recado do morro". 
Guerreiro, Antonio. Pensadores e filósofos. Público. 20 set. 2013. Disponível em: https://www.publico.pt/2013/o9/20/jornal/pensadores-e-filosofos-27103296. Acesso em: 19 set. 2019.

KagAme, Alexis. La philosophie Bantu-Rwandaise de l'Etre. Bruxelas: ARSC, 1956.

Kagame, Alexis. La philosofie bantu compare. Paris: Presence Africaine, 1976.

LARANjeira, Pires (org). Negritude africana de língua portuguesa: textos de apoio (1947-1963). Coimbra: Angelus Novus, 2000.

Massoni, Marco. Tsenay Serequeberhan: un'ermeneutica della filosofia africana. In: Procesi, Lidia; Nkemnkia, Martin Nkafu; Massoni Marco (eds.). Prospettive di filosofia africana. Roma: Edizioni Associate, 2001. p.150-169.

Matumona, Muanamosi. Filosofia africana na linha do tempo: implicações epistemológicas, pedagógicas e práticas de uma ciência moderna. Lisboa: Esfera do Caos, 2011.

Mbembe, Achille. Necropolitics. Public Culture, Durham, v. 15, n. 1, p. 11-40, 2003.

Mudimbe, Valentin Y. L'invenzione dell'Africa. Tradução de G. Muzzopappa. Roma: Meltemi, 2007.

NAncy, Jean-Luc. La comunità inoperosa. Tradução de A. Moscati. Napoli: Cronopio, 1992.

NAncy, Jean-Luc. Essere singolare plurale. Tradução de D. Tarizzo. Torino: Einaudi, 2001.

Rella, Franco. Miti e figure del moderno. Milano: Feltrinelli, 1993.

Serequeberhan, Tsenay. Theory and actuality of existence: Fanon and Cabral. In: Wiredu, Kwasi (ed.). A companion to african philosophy. Oxford: Blackwell, 2003. p. 225-230.

Tempels, R. P. Placide. Filosofia Bantu. Tradução de Amélia A. Mingas e Zavoni Ntondo. Luanda (Angola): Edições de Angola, Faculdade de Letras da UAN, 1944/2016.

VieIRA, Luandino. Luuanda: estórias. Lisboa: Caminho, 2004.

Recebido em 19 de novembro de 2019.

Aprovado em $1^{\circ}$ de março de 2020. 


\section{Resumo/Abstract/Resumen}

\section{A arma da teoria: pensamento africano e literatura}

\section{Roberto Vecchi}

O artigo procura repensar alguma caraterísticas da filosofia africana no espaço da língua portuguesa em comparação com outros contextos africanos que foram atravessados pelo processo de colonização (em particular a África francesa e inglesa). Depois dos processos de independência que se fundaram sobre pensamentos ideologicamente fortes (nomeadamente o caso de Amílcar Cabral), os tempos pós-coloniais não parecem ser marcados por reflexões radicais como ocorreu em outros âmbitos, sobretudo a partir de um enxerte favorável de diferentes pensamentos radicais. Discutindo a diferença entre filosofia e pensamento no quadro da revisão do pensamento sobre a comunidade, que desconstrói a obra identitária e as narrativas de nação, propõe-se encontrar na literatura - e não na filosofia no sentido estrito, nos contextos da África de língua portuguesa - estilhaços deste pensamento radical que se encontram disseminados em numerosos textos. Partindo do caso da reconfiguração da comunidade no clássico Luuanda de Luandino Vieira, a perspetiva que se esboça é a de um mapeamento do pensamento africano no espaço da língua portuguesa disseminado em textos literários.

Palavras-chave: filosofia africana, pensamento nos países africanos de língua portuguesa, filosofia e literaturas, comunidade, Luuanda.

\section{The Weapon of Theory: African thought and literature}

\section{Roberto Vecchi}

The article aims to review some characteristics of African philosophy in Lusophone African countries compared with other African contexts affected by colonization processes (particularly British and French Africa). After political independence, founded on a set of strong ideological thinking (in particular, the case of Amilcar Cabral), post-colonial times do not seem to be characterized by radical reflections as happened in other contexts, mainly through a favourable conjunction of new radical thinking. Discussing the difference between philosophy and thought in the context of the theoretical revision of the concept of community, deconstructing the work of identities and national narratives, the article attempts to find in literature - and not in philosophy in the strict sense, in the context of Lusophone African countries - fragments of such radical thought disseminated in numerous texts. Taking as a case study the reconfiguration of the community in the classic Luuanda by Luandino Vieira, the perspective written in the text deals with mapping of African thought in the Lusophone African countries spread across many literary texts.

Keywords: African philosophy, Thought in Lusophone African countries, Philosophy and Literature, Community, Luuanda. 


\section{El arma de la teoría: pensamiento africano y literatura}

\section{Roberto Vecchi}

Este artículo tiene como objetivo revisar algunas características de la filosofía africana en los países africanos lusófonos, en comparación con otros contextos africanos que atravesados por procesos de colonización (especialmente la África inglesa y francesa). Después de la independencia política, fundada en un conjunto de pensamientos ideológicamente fuertes (especialmente en el caso de Amílcar Cabral), los tiempos poscoloniales no parecen caracterizarse por reflexiones radicales, como si ocurrió en otros contextos, principalmente a través de una conjunción favorable de nuevos pensamientos radicales. Discutiendo la diferencia entre filosofía y pensamiento en el marco de la revisión teórica del concepto de comunidad, que deconstruye la obra identitaria y las narrativas de la nación como obra, este artículo propone encontrar en la literatura - y no en la filosofía en sentido estricto, en el contexto de los países de la África lusófona - fragmentos de ese pensamiento radical diseminados en numerosos textos. A partir del caso de la reconfiguración de la comunidad en el clásico Luuanda, de Luandino Vieira, se esboza la perspectiva un mapeo del pensamiento africano en el espacio de la lengua portuguesa diseminado en textos literarios.

Palabras clave: filosofía africana, pensamiento en países africanos lusófonos, filosofia y literatura, comunidad, Luuanda. 